\title{
Thymus and activation-regulated chemokine as a biomarker of food protein-induced enterocolitis syndrome
}

\author{
YUKA OKURA $^{1}$, Masaki Shimomura ${ }^{1}$, Yutaka Takahashi ${ }^{1}$, and Ichiro Kobayashi ${ }^{1}$ \\ ${ }^{1}$ KKR Sapporo Medical Center
}

July 1,2021

\section{Conflict of interest}

The authors declare no conflicts of interest.

\section{Financial support}

The authors did not receive support from any organization for the submitted work.

To The Editor,

Food protein-induced enterocolitis syndrome (FPIES) is a non IgE-mediated food allergy that predominantly affects infants and is characterized by repetitive vomiting 1-4 hours after causative food ingestion which often leads to diarrhea, lethargy, and pallor. Although the involvement of cellular immunity is suggested, comprehensive mechanisms of the disorder have been poorly understood. Diagnosis is often hampered by delayed onset of non-specific symptoms after allergen exposure and lack of awareness of FPIES. In addition, reliable specific biomarkers are absent, although acute FPIES attack is accompanied by neutrophilia, thrombocytosis, methemoglobinemia, and metabolic acidosis. ${ }^{1}$

Thymus and activation-regulated chemokine (TARC), a member of the CC chemokine family, recruits CC chemokine receptor $4^{+}$Th2-polarized memory/effector T cells into inflamed tissues. A serum TARC level serves as a reliable biomarker of AD disease severity in clinical practice. ${ }^{2}$ Although high levels of serum TARC discriminate FPIES from vomiting associated with infectious gastroenteritis, ${ }^{4}$ TARC levels are influenced by several factors such as age and presence of eczema, which make it difficult to evaluate FPIES by a single measurement of TARC level. A recent report has demonstrated that serum levels of TARC elevate after oral food challenge (OFC) in two patients with FPIES, suggesting that serum TARC levels are potential biomarker of the disease. ${ }^{3}$ To validate the utility of TARC in the diagnosis of FPIES, we examined TARC ratio in a larger number of patients with FPIES.

The present study enrolled patients with solid FPIES diagnosed by positive OFC results in our hospital between April 2018 and April 2021. The open OFC was performed by ingestion at a single or three-divided doses with 30-minute intervals. OFC was considered positive for FPIES by delayed abdominal reactions without immediate skin or respiratory reactions. Tolerance acquisition was defined by both (1) negative OFC and (2) ability to repeatedly consume daily intakes without FPIES symptoms for three months at home. Serum TARC levels and C-reactive protein (CRP) were measured before (pre-OFC) and 24 hours after OFC (post-OFC). TARC ratio was defined as the ratio of post-OFC to pre-OFC TARC levels. In the present study, we excluded OFC which missed the data of TARC ratio. We compared TARC ratio and post-OFC serum CRP levels between the negative and positive OFC groups. We also collected data of sex, causative food, age of onset and diagnosis, the number of previous episodes before diagnosis, specific immunoglobulin E (sIgE) to causative foods by ImmunoCAP test, and current eczema. A sIgE values higher than $0.35 \mathrm{U}_{\mathrm{A}} / \mathrm{ml}$ were defined as positive. Statistical analyses were performed using GraphPad Prism8. 
Mann-Whitney U test was used for continuous data between two groups. A correlation of TARC ratio and serum CRP after OFC was evaluated by using the Spearman correlation coefficient. A P value of $<0.05$ was considered statistically significant. This study was approved by the institutional review board of KKR Sapporo Medical Center (2020-54).

Of total 57 OFCs in 25 patients, seven OFC were excluded because of missing data of TARC ratio. As a result, TARC ratio was analyzed in 50 OFC of 23 patients which consisted of 22 OFC for diagnoses and 28 OFC for evaluations of tolerance. Characteristics of patients were shown in Table 1. Tested foods for OFC were 36 for egg yolk (EY), 10 for wheat, 3 for scallop, and 1 for soy. Forty-two (84.0\%) of all OFC were positive. Eight negative OFC (eight patients) were all confirmed acquisition of tolerance later.

As shown in Figure 1, the median TARC ratio was significantly higher in the positive OFC group than in the negative OFC group (3.85 vs $1.15, \mathrm{p}=0.018)$. The pre-OFC CRP levels were all negative $(\mathrm{n}=50$, median $0.02 \mathrm{mg} / \mathrm{dL}$, IQR $0.01-0.03 \mathrm{mg} / \mathrm{dL}$ ). The median of post-OFC CRP levels in the negative and the positive OFC groups were $0.02 \mathrm{mg} / \mathrm{dL}(\mathrm{n}=8$, IQR $0.01-0.05 \mathrm{mg} / \mathrm{dL})$ and $0.51 \mathrm{mg} / \mathrm{dL}(\mathrm{n}=42$, IQR 0.23-1.70 $\mathrm{mg} / \mathrm{dL})$, respectively $(\mathrm{p}=0.027)$. Additionally, there was a weak positive correlation between TARC ratio and post-OFC CRP levels $(\mathrm{r} 2=0.699, \mathrm{p}<0.0001)$.

\section{Discussion}

We showed that solid FPIES reaction on OFC is accompanied by an elevation of TARC ratio. Our study included eight OFC (six cases) which pre-OFC TARC levels were over upper limit of age-appropriate value (data not shown). Two of six cases had eczema, however, the other four cases lacked eczema. These suggested that TARC ratio could be available regardless of baseline serum TARC levels.

TARC ratio correlated with post-OFC CRP levels. A recent study demonstrates that CRP levels increase in positive OFC suggesting inflammatory mechanisms in FPIES. ${ }^{4}$ FPIES is thought to be a T cell-mediated disorder, leading to local $\mathrm{T}$ cell infiltration with exaggerated expression of proinflammatory cytokines such as tumor necrosis factor- $\alpha$ and suppression of anti-inflammatory cytokine, transforming growth factor- $\beta .{ }^{5}$ An acute FPIES reaction is also associated with a skewing of the T cells cytokine profiles to Th2 response. ${ }^{6}$ On the other hand, regulatory $\mathrm{T}$ cells may play a role in the acquisition of tolerance. ${ }^{7}$ TARC promotes intestinal inflammation and counteracts regulatory $\mathrm{T}$ cell-mediated protection from colitis in mice. ${ }^{8}$ Indeed, TARC expression is enhanced in the intestine of experimental allergic mice with diarrhea, ${ }^{9}$ although little is known about the pathological roles of TARC in $\mathrm{T}$ cell homing to the intestinal mucosa. These findings suggest that TARC is involved in the development of intestinal inflammation of solid FPIES. In contrast to OFC-positive patients, TARC levels showed no changes in any OFC-negative patients who finally achieved tolerances of solid FPIES. Thus, TARC ratio might be used to predict tolerance acquisition.

Our study is limited by retrospective review of small number of patients from a single institute. Additionally, elicited foods were limited to EY, wheat, scallop, and soy. Since not all OFC-positive patients showed elevation of serum TARC levels after OFC, further study is necessary to investigate correlations between TARC ratio and severity, doses of challenge, or causative foods.

In conclusion, TARC ratio may be a potentially useful biomarker to diagnose and manage solid FPIES irrespective of the presence of eczema. An understanding the pathological roles of TARC may provide new strategy for the management of solid FPIES.

\section{Keywords}

Food protein-induced enterocolitis syndrome; thymus and activation-regulated chemokine; oral food challenge; child

\section{Acknowledgments}

We thank all patients who participated in this study.

\section{Impact statement}


Thymus and activation-regulated chemokine (TARC) ratio may be used as a potential biomarker for diagnosis and tolerance acquisition of solid food protein-induced enterocolitis syndrome regardless of baseline serum TARC levels.

\section{References}

1. Caubet JC, Nowak-Wegrzyn A. Current understanding of the immune mechanisms of food protein-induced enterocolitis syndrome. Expert Rev Clin Immunol. 2011;7:317-327.

2. Fujisawa T, Nagao M, Hiraguchi Y, et al. Serum measurement of thymus and activation-regulated chemokine/CCL17 in children with atopic dermatitis: elevated normal levels in infancy and age-specific analysis in atopic dermatitis. Pediatr Allergy Immunol. 2009;20:633-641.

3. Hamano S, Yamamoto A, Fukuhara D, Yan K. Serum thymus and activation-regulated chemokine level as a potential biomarker for food protein-induced enterocolitis syndrome. Pediatr Allergy Immunol.2019;30:387389.

4. Pecora V, Prencipe G, Valluzzi R, et al. Inflammatory events during food protein-induced enterocolitis syndrome reactions. Pediatr Allergy Immunol. 2017;28:464-470.

5. Chung HL, Hwang JB, Park JJ, Kim SG. Expression of transforming growth factor beta1, transforming growth factor type I and II receptors, and TNF-alpha in the mucosa of the small intestine in infants with food protein-induced enterocolitis syndrome. J Allergy Clin Immunol.2002;109:150-154.

6. Morita H, Nomura I, Orihara K, et al. Antigen-specific T-cell responses in patients with non-IgE-mediated gastrointestinal food allergy are predominantly skewed to T(H)2. J Allergy Clin Immunol. 2013;131:590-592 e591-596.

7. Karlsson MR, Rugtveit J, Brandtzaeg P. Allergen-responsive CD4+CD25+ regulatory T cells in children who have outgrown cow's milk allergy.J Exp Med. 2004;199:1679-1688.

8. Heiseke AF, Faul AC, Lehr HA, et al. CCL17 promotes intestinal inflammation in mice and counteracts regulatory T cell-mediated protection from colitis. Gastroenterology. 2012;142:335-345.

9. Knight AK, Blazquez AB, Zhang S, Mayer L, Sampson HA, Berin MC. CD4 T cells activated in the mesenteric lymph node mediate gastrointestinal food allergy in mice. Am J Physiol Gastrointest Liver Physiol.2007;293:G1234-1243.

\section{Figure Legends}

\section{Figure 1}

(A) Comparison of TARC ratio between negative and positive oral food challenge (OFC) groups.

(B) Comparison of post-OFC CRP levels between negative and positive OFC groups.

(C) Correlation of TARC ratio and post-OFC CRP levels.

Square: negative OFC. Circle: positive OFC.

\section{Hosted file}

Figure 1.pptx available at https://authorea.com/users/423043/articles/528606-thymus-andactivation-regulated-chemokine-as-a-biomarker-of-food-protein-induced-enterocolitissyndrome

\section{Hosted file}

Table 1.xlsx available at https://authorea.com/users/423043/articles/528606-thymus-andactivation-regulated-chemokine-as-a-biomarker-of-food-protein-induced-enterocolitissyndrome 